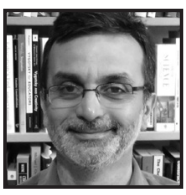

\title{
The Art \& Science Project: Constructing Knowledge Through Creative Assessments
}

\author{
Jailson Lima, Vanier College
}

\begin{abstract}
In the last few years, the use of creative assessments has been shown to be effective in addressing students' different learning styles and nurturing their personal and academic growth. This article presents the framework for the activities and assessments of the Art \& Science Project, ${ }^{1}$ which is designed to engage learners by using visual arts to portray scientific concepts. The project's goal is to promote cross-disciplinary integration and a deeper understanding of the crucial role of models in science. The history of the project and the technologies used to support a creative environment are described.
\end{abstract}

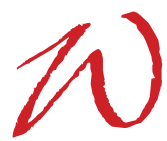

hile I did not experience difficulties as a student, frustration and dissatisfaction were pervasive during my high school years as a result of instructional strategies that were disengaged from life experiences and assessments that did not contribute to developing, inciting, or sustaining intellectual curiosity. The assumption that the transmission of factual knowledge was the most important thing happening in the classroom hindered the school experience and failed to spark curiosity and passion for learning. Csikszentmihalyi (1997) underlines that becoming dissatisfied with knowledge and rejecting it triggers the creative process. In retrospect, my unfulfilling experiences as a student catalyzed my interest in establishing relationships among disciplines and constructing meaning about the world.

In this article, I offer readers a description of my journey to become a chemistry teacher who explores art as a tool for learning in college science courses in Quebec. 
The next section recalls my first interactions with creative assessments in a culturally different school environment, in Brazil. I then explain the role of professional development in my adjusting to teaching in Quebec. This is followed by a summary of my first attempts to incorporate creative assignments to enhance learning with a Liberal Arts cohort. A description of the technologies that are used to support a creative environment is given, followed by curriculum adjustments needed to incorporate art into the science classroom. I also review the literature to give theoretical foundations for this instructional strategy. This paper concludes with an explanation of the assessment and a brief analysis of students' responses to it.

\section{Teaching Outside the Box: The Early Years}

Chemistry has been my favorite subject since my first introductory high school course. Sparked by this interest, I studied the discipline for 14 years before becoming a full-time certified teacher. During this period, I completed a B.S. and an M.S. in Chemistry, a teaching certificate, and a Ph.D. in Inorganic Photochemistry from the University of São Paulo in Brazil. These academic degrees provided material to achieve disciplinary literacy (Carney \& Indrisano, 2013) that includes the content knowledge, general-pedagogical knowledge, and curricular knowledge in chemistry. Since the beginning of my teaching career, I have been exposed to innovative and creative approaches that had a profound effect in shaping my pedagogical content knowledge (Shulman, 2013), which served as the foundation for the Art \& Science Project.

Teaching high school chemistry in the 1990s at the Colégio Vera Cruz in São Paulo became a watershed event in my teaching practice. An environment rich in appropriate stimuli, the school developed a pedagogical approach based on teaching for understanding within and across disciplines to empower students to grow intellectually throughout their lives. The administration promoted the use of multidisciplinary projects to make learning dynamic and meaningful. For example, Palimpsest was a project in which students were asked to look at cities as something having diverse layers or aspects that usually remain hidden beneath the surface. In the first phase of the project, students explored the landscape of the school's neighborhood to illustrate its urban development from a historical point of view. Later, the project focused on the city of Rio de Janeiro during the 19th century, a period in which the city was the nation's capital. Excerpts of novels, essays, official documents, and paintings of the period were used to contextualize and integrate the different disciplines-history, geography, literature, and the visual arts. The topics were complementary and created 
a mosaic that was analyzed through a multidisciplinary perspective. The group took a field trip to Rio de Janeiro in search of the 19th-century layers of its modern palimpsest-governmental buildings, historical houses, commercial centers, and the old port. After the trip, students watched movies based on literary works of that period, which gave them the opportunity to experience 19th-century novels through the lenses of 20th-century cinema. The pre-readings, field trip, and post-activities created a continuum that helped students develop a sense of seeing cities as palimpsests.

In another multidisciplinary project that involved literature and the visual arts, twelfth graders developed performances that included both visual and performing arts to portray the characteristics of avant-garde art movements-Impressionism, Fauvism, Dadaism, Cubism, Futurism, Expressionism-and their connections to the literary styles of the period. By attending students' presentations, I began to understand the potential of creative assessments that involve visual arts to promote the integration and consolidation of knowledge. Students create meaning through symbolic visual representations linked to their cultural heritage, while developing new perceptions of visual forms (Hickman \& Eglinton, 2015). These innovative projects were inspiring, and witnessing their execution provided me a glimpse of the inherent complexity of curriculum integration and the necessity of investing time, energy, and intellectual effort on the part of all teachers involved.

In 1997, the successful landing of the roving probe Pathfinder on the surface of Mars made the headlines in the media (Raeburn, 1998) and inspired my first attempt to incite students' imaginations in science using astronomy as a unifying center. With the intrinsic limitations of the pre-Internet era, I began to search for learning activities to visually engage students with astronomy. A mobile planetarium was set up in the school's gymnasium to offer a series of presentations that covered Newton's law of gravitation (Feynman, 1995) and the genesis of the chemical elements in stars (Chown, 2001; Hartquist \& Williams, 1995) with the goal of triggering fruitful discussions among students and teachers. This activity created awareness of fundamental underlying principles such as gravity, conservation of energy (Smil, 1999), and the important concept that the same chemical elements that exist on Earth (Cox, 1995) also make up all matter in the universe (Hudson, 2006) and serve as building blocks for all living organisms (Schrödinger, 1992; Williams \& Silva, 1996).

Taking into account the level of intellectual development of our high school students, we designed lessons that illustrate how the concepts in chemistry, physics, and biology guide the understanding of the world. The construction of science literacy had the goal of integrating disciplinary knowledge to serve as foundation for a multidisciplinary, 
creative science project. For example, I introduced unusual chemical compounds that had been detected in interstellar space (Shaw, 2006) to bring awareness that the structures and reactions of chemical substances given in textbooks are based on their reactivity patterns on or near the Earth's surface (Wayne, 1991). However, those patterns can change remarkably under the very different conditions of temperature, pressure, and electromagnetic radiation that are found in space (Hudson, 2006), an idea that is not emphasized in introductory chemistry courses.

In 2000, I immigrated to Canada before the group developed the project further. Although I was not involved again with a multidisciplinary science project for another decade, my expectations and beliefs about teaching and learning were forever changed by interacting with peers in such an electrifying social environment that recognized the importance of fostering imagination and creativity.

\section{Teaching College in Canada: Professional Development and Inspiration}

Since both the format and cultural background of the CEGEP system in Quebec are quite different from those of the educational system in Brazil, my first years at Vanier College were spent adjusting to my new teaching environment. With the goal of bringing new perspectives to my practice, I started the University of Sherbrooke's Performa Master Teacher Program, an M.Ed. program that is tailored to the needs of college teachers. Its courses provide contact with the groundbreaking ideas of Lev Vygotsky, Kieran Egan, Ken Robinson, Paulo Freire, Elliot Eisner, Seymour Papert, and Eric Mazur, among others. The Performa program was truly inspiring and showed me that developing ideas for innovative, less conventional approaches to teaching requires genuine effort and hard work. In the course, Constructing Knowledge Across the Disciplines, we analyzed both the conceptual framework and the challenges of interdisciplinarity. This course offered me the opportunity to reflect on my early multidisciplinary experiences in Brazil, seeing them against the backdrop of the extensive literature in the field. I was able to understand the theoretical underpinnings that made my experience at Colégio Vera Cruz so rewarding for both students and teachers. Understanding the conceptual framework of interdisciplinarity gave me the incentive to explore it in a course that I teach at Vanier College. The next section recounts the first attempts at putting the knowledge gained in the Performa program into practice. 


\section{Science Meets Liberal Arts}

In 2009, I started teaching History and Methodology of Science, a mandatory fourth-semester course for Liberal Arts students. Sparking students' interest in science is a challenge when they have an insufficient background from high school and a disdain of mathematical formulas and calculations. Despite these shortcomings, the majority of Liberal Arts students have good writing skills and possess curious, inquiring minds. In the last semester of their program, their knowledge of history, philosophy, and culture is definitely above what can be expected from an average college student.

Traditional teacher-centered approaches that are employed at the college level are usually based on the need for conformity and standardization, and they tend to treat learning as a series of steps to be mastered. Since such approaches are not well suited to Liberal Arts students, I had to search for alternatives to deliver the course content. My main objective was to provide learning experiences to nurture the students' personal and academic growth in ways for them to develop creative minds and become critical thinkers. I found inspiration to accomplish these goals in Ken Robinson's (2006, 2010) TED Talks about creativity and Kieran Egan's $(2005,2007,2008)$ books on the importance of imagination in fostering learning.

Believing in the importance of constructing knowledge across the disciplines, I envisioned links between the students' previous knowledge in philosophy, history, and art with the content of the science course. For example, students were invited to establish links between the groundbreaking works of Sigmund Freud, Pablo Picasso, and Albert Einstein in the early 20th century. Freud's theories about the crucial role of the unconscious in determining human behaviour placed emotions and sensations as more important than rational thought. During the same period, Picasso began experimenting with deconstructing forms to portray the world away from classical, realistic descriptions. In 1905, Einstein proposed the wave-particle duality of light to explain the photoelectric effect as part of a counterrevolution in science that challenged the objectivity of classical Newtonian mechanics. Students were intrigued by the connections between science and art, and they started seeing science differently, as part of a complex web that links aspects of art and philosophy to the political and economic realities of a given historical period.

Becoming aware of the immense potential of creativity and imagination to enhance learning and transfer knowledge, I combined the ideas of Robinson (2006, 2009, 2010, 2011) and Egan $(2005,2007,2008)$ with the multidisciplinary project that integrated art and literature at Colégio Vera Cruz to propose a big assignment in which students 
used visual arts to portray some of the scientific concepts that we studied in the course. Overall, the results with the first cohort were below my expectations due to the lack of proper communication with students to explain the scope and purpose of the assignment. Bransford, Brown, and Pellegrino (2000) point out the necessity of providing enough time for students to process information and seek feedback about their progress. According to these authors, transfer can be enhanced by teaching a topic in multiple contexts, which includes giving examples that demonstrate the wide application of what is being taught. I was also inspired by the intensive process that Picasso underwent while drawing the preliminary sketches for Les demoiselles d'Avignon, his 1907 early creative breakthrough (Gardner, 1993). I realized that students need more time to digest their own ideas as part of a constant dialogue with the teacher outside the classroom - a goal that can be accomplished with the use of technology. The next section covers the technologies that support the Art \& Science Project.

\section{Creating a Draft Through Google Docs}

Providing enough time to reflect, share perspectives, and exchange ideas is crucial when planning instructional strategies for creative assignments. In order to provide feedback on students' drafts, I used Google Docs as a platform for asynchronous dialogues. We discussed the scientific concepts that caught their attention and how they could portray these ideas using visual arts. Once they had chosen the science component of their artwork, an art teacher could give them feedback on the materials, colors, and techniques they could use. Mimicking Picasso's creative process that had been previously analyzed in class, a student would draw a rough sketch, upload it to Google Docs, and discuss it with both teachers. The exchange of ideas gave them encouragement and boosted their confidence. The quality of the artworks improved substantially as a result of timely feedback. Google Docs was found to be a good platform on which to develop the drafts of the artwork. Perfecting the draft is a milestone that forces students to become actively engaged during the initial phase of the multi-week project. It also provides a necessary channel of communication between the teachers and each student prior to tackling the artwork itself.

After handing in the final version of their artwork and presenting it to their peers, students wrote a self-reflective learning journal in which they assessed their own artwork based on a rubric that had been provided. They were required to comment on the strengths and weaknesses of their work as well as how they would do it differently if they had the chance. In a project of this scope, the process is as important as the product. 
Teaching science through art resonated well with the Liberal Arts cohort. This experience was so personally enriching that I decided to bring this crossfertilization to science students the following year. Although the format of the assignment was maintained, I had to adapt the creative activities that are assessed with the main competencies of the science courses. This new framework is discussed in the next section.

\section{Theoretical Foundations for the Project}

The main difficulty in learning chemistry lies in the fact that there are three distinct types of representations (Gilbert \& Treagust, 2009). The first type is the phenomenological, which encompasses the representation of material properties either observed in everyday contexts or measured in laboratory settings. The second type deals with the models used to explain all of these observed phenomena. These models are highly abstract and involve sub-microscopic entities such as molecules, atoms, ions, and radicals (Floriano, Reiners, Markic, \& Avitabile, 2009). The third type is the symbolic type, which includes the representations of chemical transformations through chemical equations, the structural formulas of chemical compounds, their spatial arrangement, as well as all the symbols and conventions displayed in figures, diagrams, and charts (Eilam \& Gilbert, 2014, Frankel \& DePace, 2012).

A coherent and sophisticated conceptual understanding of the discipline that enables students to select the appropriate model in each context is an important competency in college chemistry courses. In terms of the stage of the intellectual development (Baxter-Magolda, 1992), the majority of incoming CEGEP students have a dualistic view of knowledge in which something is either right or wrong. In high school, science was learned by memorizing a collection of facts and procedures of increasing complexity, without any sort of reflection about the ways of knowing. Within this framework, science is presented as a field where objective reality is supreme. This approach to learning leads to knowledge fragmentation in which subsequent chunks are constantly replaced by new sets of "absolute truths," which reiterates the dualism that characterizes the first stages of intellectual development. Although it is true that the vast majority of high school students tend to conceptualize knowledge in a dualistic view, it is noteworthy to mention that traditional ways of teaching not only emphasize this belief, but also prevent the necessary self-reflection to challenge them. It is hard for students to change their initial beliefs in an environment where conformity, standardization, and rigor in knowledge generation are the most 
important cultural values. However, to understand the relationships between the three types of representations that are used in chemistry, this dualistic view must be constantly challenged by emphasizing the high-level abstractions of the models and their apparently inconsistent representations (Taber, 2009), such as the wave-particle duality and the various atomic models. It is commonplace to teach science as if finding a reasonable solution for a practical problem is its ultimate goal. It is crucial to instill in students, especially in their early stages of schooling, the idea that there are intrinsic limitations in scientific models, and we must continually evaluate the legitimacy of working with those models.

College students struggle with the idea that knowledge is neither fixed nor universal, but is instead constructed within a specific context. Artistic expression has the potential to help science students understand that the concept of absolute truth is neither scientifically nor epistemologically justified. Using art to foster imagination and promote learning has been historically considered a fundamental characteristic in the cognitive life of both pre-school and primary school children (Halpine, 2004; Heid, 2008; Paige \& Whitney, 2008). Some attempts to implement similar approaches in higher education (Furlan, Kitson, \& Andes, 2007; Halpine, 2008; Lunn \& Noble, 2008) have shown to be effective by influencing the motivation components, which are ultimately related to student involvement in learning and academic achievement. The inclusion of an art project in college science courses is an innovation that not only took into account the Quebec ministerial requirements, but also fulfills the need for coherence between instruction, curriculum, and assessment (Fink, 2003; Weimer, 2002; Wiggins \& McTighe, 2005). By expressing their conceptual understanding using art and imagination, students can enhance their cognitive capacity by seeing things other than in the way they are formally represented. Art can become a unifying center in the curriculum to enrich students' cultural development by contextualizing scientific concepts within historical and philosophical frameworks (Efland, 2002).

The teaching of chemistry tends to overemphasize the symbolic representations at the expense of neglecting the construction of the concepts in a meaningful way (Cracolice, 2005; Krajcik, Slotta, McNeill, \& Reiser, 2008). Students commonly mistake the ideas for the symbols used to represent them: Being able to read the symbols has no direct correlation with understanding the concepts they represent (Floriano et al., 2009). There is a strong tendency to teach through dogma, mechanically solving problems, and rote memorization of pieces of information that are not integrated in students' previous knowledge. As a consequence, students tend to compartmentalize information into tidy, demarcated packets, which compromises their conceptual understanding, curriculum integration, and construction of knowledge. 
The works of the Belgian painter René Magritte can be useful illustrations of the notion of symbolic representation. His paintings frequently portray juxtaposed ordinary objects displayed in unconventional, unexpected contexts that bring viewers new interpretations that are somewhat disruptive to consider. His iconic masterpiece, The Treachery of Images (1929), depicts a pipe with the disclaimer, "This is not a pipe," which implies that it is an image of a pipe. In The Human Condition (1934), the painting within the painting perfectly captures the scene behind it, which is paradoxical because the image can never equal reality. Students are invited to associate the idea of these paintings to the fact that all atomic models studied in the course are only representations of an atom and not the atom itself. It might look obvious to an expert, but the realization helps students understand the high level of abstraction of chemical models and give them an appreciation for the images, symbols, and conventions used in the field. As outlined by Frankel and DePace (2012), "visual representations are critical components of science research. Images engage us in ways that words cannot" (p. 3).

The assignment given to science students in the Art \& Science Project requires them to choose a theme of interest in chemistry and to create a visual representation of it that portrays some of the nine core ideas in the field (Atkins, 2010; Talanquer, 2016), namely the atomic nature of matter, chemical bonds, periodic properties, molecular shape, intermolecular forces, types of chemical reactions, energy conservation, entropy, and barriers to reactions. By exploring these "big ideas" and the ways they interconnect, students can acquire deeper conceptual change by crossing threshold concepts (Meyer \& Land, 2003; Talanquer, 2015), which are transformative, integrated, irreversible, and troublesome concepts that expand the disciplinary boundaries and the ways of thinking in a discipline.

The concept map shown in Figure 1 outlines the nine big ideas covered in the three main chemistry courses that are offered in the CEGEP system: General Chemistry (Chem-NYA), Chemistry of Solutions (Chem-NYB), and Organic Chemistry I (Chem-HTJ). It also shows how these big ideas interconnect and are linked to more complex concepts, such as the relationship between structure and reactivity and the role of both thermodynamic and kinetic parameters in chemical reactions. Exposing college students to this sophisticated, integrative view challenges the misconceptions they bring from high school by offering an expert view of chemistry. 


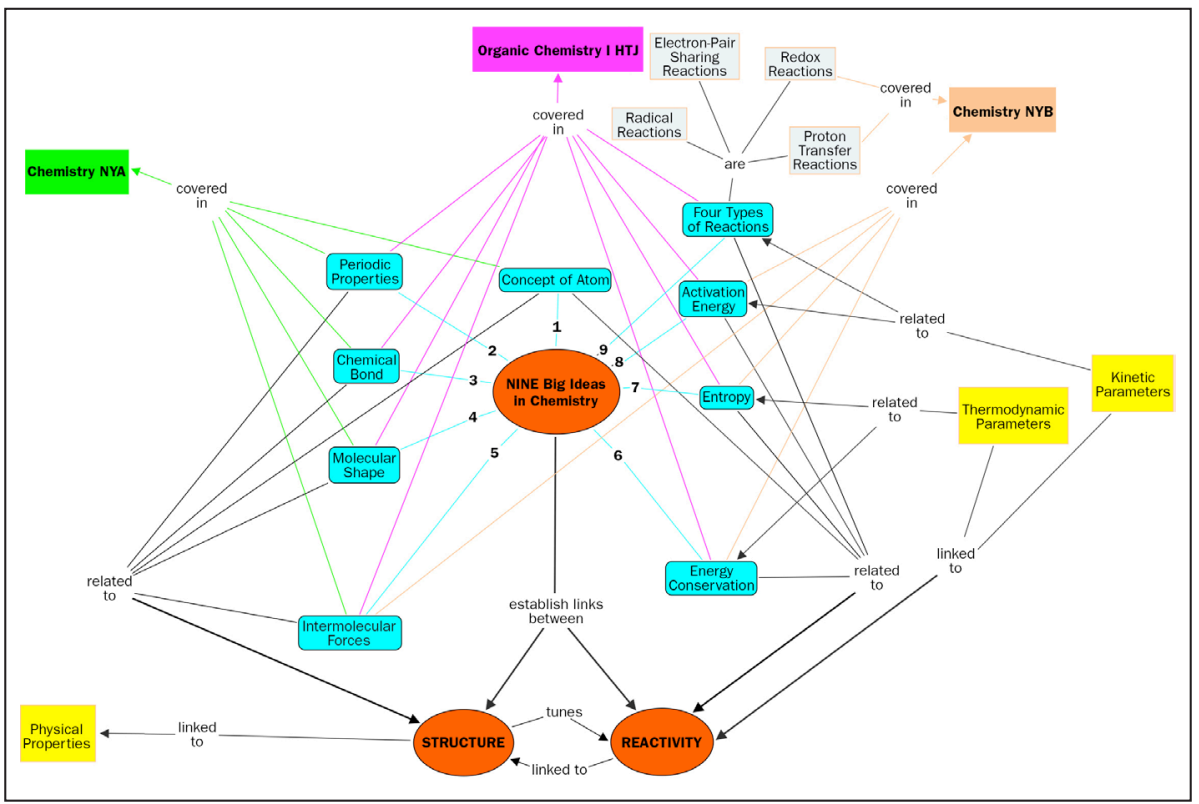

Fig. 1: Concept map of the nine "big ideas" in chemistry proposed by Peter Atkins that are covered in General Chemistry (NYA), Chemistry of Solutions (NYB), and Organic Chemistry I (HTJ). These ideas are an integral part of the artwork created by science students.

The artwork assignment addresses relevant features from social constructivism (del Rio \& Álvarez, 2007) and constructionism. Constructionism shares constructivism's connotation of learning as "building knowledge structures" irrespective of the circumstances of the learning. It then adds "the idea that this happens especially felicitously in a context where the learner is consciously engaged in constructing a public entity, whether it's a sand castle on the beach or a theory of the universe" (Papert \& Harel, 1991, p. 1). In the Art \& Science project, learning occurs through a process of discovery that is mediated by social interactions between peers and teachers in a stimulating environment. As long as the scientific ideas portrayed are consistent with the views currently held by the scientific community, students have the final word on the themes and artistic choices they choose for their artwork. This freedom reinforces a sense of ownership and the value of learning by connecting the artwork with their own lives, passions, and interests (Grohman \& Szmidt, 2013; Ritchhart, 2015) while encouraging them to self-reflect (Bruner, 1986). Based on such a personal outlook, this activity has the potential to engage students cognitively at higher levels of abstraction by enhancing their engagement and their ability to transfer knowledge across disciplines in school, as well as from school to both home and the workplace. 
Students are encouraged to choose a topic of interest and a medium that best suits their artistic skills. For example, Figure 2 depicts an arts-and-crafts piece that portrays the evolution of atomic models - the most fundamental threshold concept in chemistry (Atkins, 2010; Feynman, 1995; Park \& Light, 2009; Pullman, 1998).

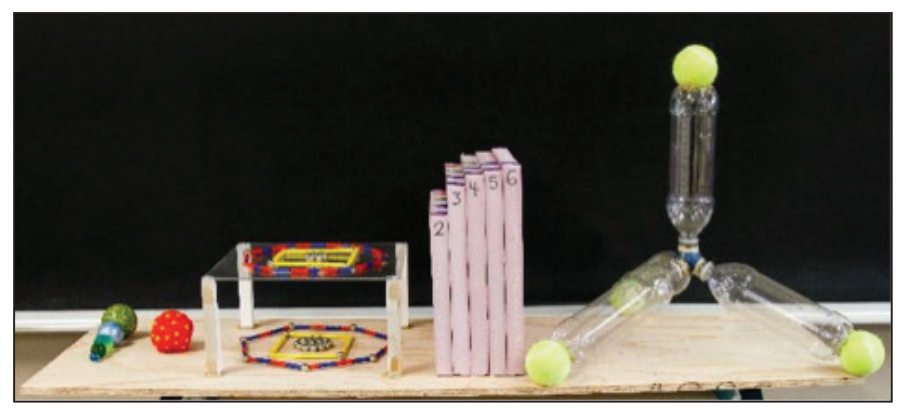

Fig. 2: An artistic representation of the evolution of atomic models

Other students opt to create a cartoon-like painting like the one shown in Figure 3, which addresses the wave-particle duality of electrons and the weirdness of quantum theory (Gamow, 1993; Rae, 1994). The artwork depicted in Figure 4 uses a combination of photography, digital manipulation of images, painting, and collage to illustrate the handedness of chemical structures and the enantioselectivity in the natural world-a fundamental concept in organic chemistry (Ball, 1994). The following section gives an explanation of the assessment and a brief analysis of students' work.

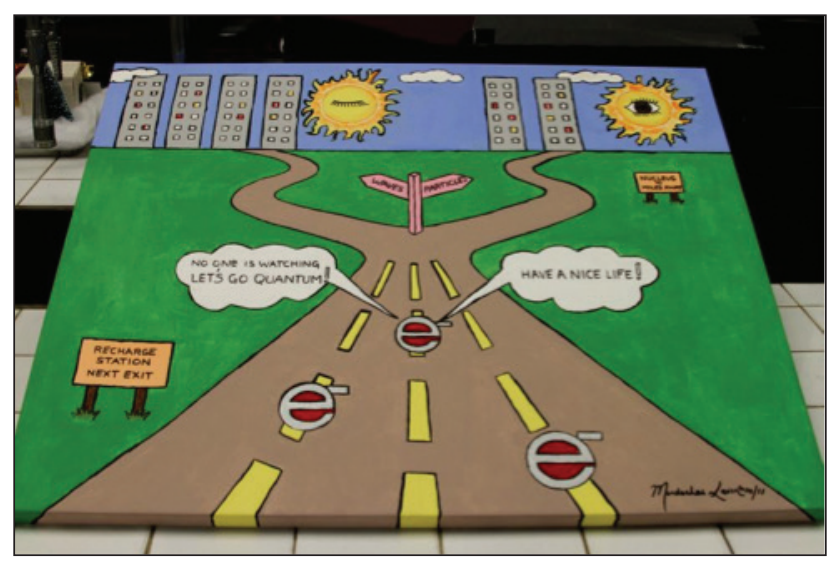

Fig. 3: Let's go quantum! portrays the weirdness of wave-particle duality 


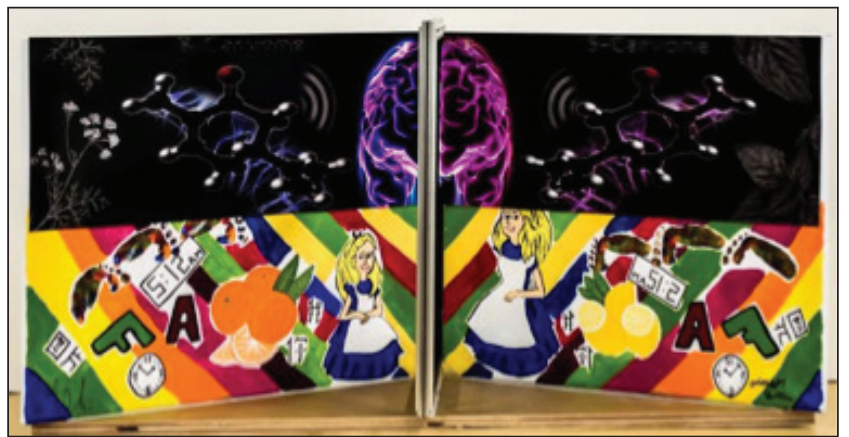

Fig. 4: Alice through the looking glass explores species that cannot be superimposed on their mirror images

\section{Assessing Students' Work}

Assessments in the form of projects that require intensive reflection over an extended period provide opportunities for critical feedback and revision through a process in which students refine and reconstruct their ideas. During the four-week project, students use creativity and lateral thinking to produce an artwork that captures the big ideas in chemistry. This activity takes place outside the classroom, but with almost-daily asynchronous communication through Google Docs to get feedback from teachers.

Assessing their learning involves multiple components: a draft of the artwork, the artwork itself, a presentation to their peers, and a self-evaluation. The process is individualized and empowers students to pursue their own interests, make their choices, and create something unique. In the draft documented in Google Docs, student and teacher discuss how the big ideas can be incorporated into the chosen theme and how to then translate these ideas into symbolic visual representations that can be decoded by viewers. The role of the teacher is to be a resource that provides constant support and guidance upon request, but does not interfere with students' choices. During the draft phase, misconceptions that students might have can be identified and challenged in ways that would not be possible in traditional pedagogies. After four weeks, the length of the Google Docs is typically about six pages, but it has varied from two to 25 pages depending on student involvement, interest, engagement, and time available to dedicate to such a labor-intensive task. 
After the completion of the work and its presentation to peers, students write a rationale that explains the meaning of the symbolic representations in their visual creation. The rationale is expected to have enough complexity to show the connections among, at least, five big ideas in chemistry.

The self-evaluation is based on a rubric that is made available in the first week of the activity. The criteria include the ability to make connections, student engagement during the process of creation, the originality, creativity, and complexity of the artwork, as well as the quality of the written rationale. Students also write a short self-reflection about how their views changed during the course when compared to previous chemistry courses. Emphasis is placed not only on the final product, but especially on the process that involves active engagement, trial and error, and higher-order cognitive levels of thinking that are important at the college level where students' intellectual maturity has not yet reached its peak.

As observed in any type of assessment, student achievement varies considerably depending on the level of engagement and interest. Since the first cohort in 2010, this activity has helped many students acquire noticeable gains in conceptual understanding, which became evident through the analysis of their drafts, rationales, and self-evaluations. Due to the prevalence of traditional teacher-centered approaches in the majority of science courses in CEGEPs, there is still resistance from many students to engage in active-learning activities, which are perceived as being excessively timeconsuming. Since this assessment differs significantly from the reality in which tests, quizzes, and lab reports are the norm, students sometimes feel stressed and resentful. My experience has shown that it is crucial to convince them of the pedagogical value of the activity to have an impact on the way they reconceptualize the role of mental models in science.

\section{Conclusion}

Traditional forms of assessment emphasize control, discipline, and selection in a culture in which assessments are mostly seen by students as negative, stressful, final high-stakes tasks that rarely enhance learning. Within the framework of this project, the paradigm shifts towards a formative assessment that encompasses extensive feedback, goal transparency (i.e., students know how the artwork will be evaluated and the assessment's relevance to their learning the course material), and intrinsic motivation for learning since it can potentially bring joy to the learning process. 
The proposed activity can be characterized as being student centered, and promoting both cooperation over competition, plus quality over quantity of learning, all common features of constructivist pedagogies.

Although still incipient, the development of a curriculum to foster imagination and creativity in the teaching of science has become a noticeable trend in the current literature (Egan, 2005, 2007; Jackson, Oliver, Shaw, \& Wisdom, 2006), not only to attract students to science programs, but also to fulfill the market's constant demand for innovation and originality.

Compared to the traditional instructional strategy-the pervasive lecture/drill/ practice-used in science courses, this activity embodies a remarkable shift in philosophy of teaching, curriculum design, and pedagogy. Students are asked to assume a more active role in their learning process by constructing meaning through a high-level cognitive activity. There is also an incentive to think creatively, an uncommon characteristic in traditional approaches.

By conducting this project, I truly believe that creativity and imagination should be stimulated and rewarded at the college level. I no longer think that success in teaching means getting the whole group of students to converge on a uniform, standard orthodox approach. Instead of an emphasis on indoctrination and homogenization, I believe, now more than ever, that we should encourage students to question the value and limitations of what is being taught. I truly believe that the joy of learning is to be found along the journey, rather than at the destination. Embracing creativity and imagination as structuring activities in higher education requires a shift in thinking to a new culture of learning in which the environment plays a major role, privileging play, questioning, and self-reflection. Within this paradigm, learning occurs as a result of synergy that takes into account stakeholders and their relationship with knowledge construction in a mutually reinforcing way. The goal is to take the interdisciplinary world around us and make it part of our experience, thus re-creating it.

The potential of such pedagogical approaches is promising and deserves to be further analyzed. As stated by Eisner (2002):

Inviting students to use their imagination means inviting them to see things other than the way they are. And, of course, this is what scientists and artists do; they perceive what is, but imagine what might be, and then use their knowledge, their technical skills, and their sensibilities to pursue what they have imagined. (p. 199) 


\section{Note}

1. The Art \& Science website (www.artandchemistry.ca) was created to showcase the achievements of this project. Students find there a repository of links to professional artists, museums, art galleries, and TED talks related to the assignment. The most relevant feature of the website is the Student Galleries, which display artworks and rationales from students in previous Liberal Arts and Science cohorts. The website is also a means of validation for the students' work by highlighting their immense creative potential and the process by which science students see art-and liberal arts students see science-differently.

\section{References}

Atkins, P. (2010). Chemistry's core ideas. Chemistry Education in New Zealand, August, 8-12.

Ball, P. (1994). Designing the molecular world: Chemistry at the frontier. Princeton, NJ: Princeton University Press.

Baxter-Magolda, M. (1992). Teaching responsively to different ways of knowing. In Knowing and reasoning in college. Genderrelated patterns in students' intellectual development (pp. 227-268). San Francisco: Jossey-Bass.

Bransford, J. D., Brown, A. L., \& Pellegrino, J. W. (Eds.) (2000). Effective teaching: Examples in history, mathematics, and science. In How people learn: Brain, mind, experience and school (pp. 155-189). Washington, DC: National Academy Press.

Bruner, J. (1986). Actual minds, possible worlds. Cambridge, MA: Harvard University Press.

Carney, M., \& Indrisano, R. (2013). Disciplinary literacy and pedagogical content knowledge. Journal of Education, 193(3), 39-49.

Chown, M. (2001). The magic furnace: The search for the origin of atoms. New York: Oxford University Press.
Cox, P. A. (1995). The elements on earth: Inorganic chemistry in the environment. New York: Oxford University Press.

Cracolice, M. S. (2005). How students learn: Knowledge construction in college chemistry courses. In N. J. Pienta, M. M. Cooper, \& T. J. Greenbowe (Eds.), Chemists' guide to effective teaching (pp. 12-27). Upper Saddle River, NJ: Pearson.

Csikszentmihalyi, M. (1997). Creativity: The psychology of discovery and invention. New York: Harper Perennial.

del Rio, P., \& Álvarez, A. (2007). Inside and outside the zone of proximal development: An ecofunctional reading of Vygotsky. In H. Daniels, M. Cole, \& J. V. Wertsch (Eds.), The Cambridge companion to Vygotsky (pp. 276-303). New York: Cambridge University Press.

Efland, A. D. (2002). Art and cognition: Integrating the visual arts in the curriculum. New York: Teachers College Press.

Egan, K. (2005). An imaginative approach to teaching. San Francisco: Jossey Bass.

Egan, K. (2007). Imagination, past and present. In K. Egan, M. Stout, \& K. Takaya (Eds.), Teaching and learning outside the box: Inspiring imagination across the curriculum. New York: Teachers College Press. 
Egan, K. (2008). The future of education: Reimagining our schools the ground up. New Haven: Yale University Press.

Eilam, B., \& Gilbert, J. K. (2014). The significance of visual representations in the teaching of science. In B. Eilam \& J. K. Gilbert (Eds.), Science teachers' use of visual representations (pp. 3-28). New York: Springer.

Eisner, E. W. (2002). The arts and the creation of mind. New Haven: Yale University Press.

Feynman, R. P. (1995). Six easy pieces: Essentials of physics explained by its most brilliant teacher. New York: Addison-Wesley Publishing co.

Fink, L. D. (2003). Creating significant learning experiences: An integrated approach to designing college courses. San Francisco: Jossey-Bass.

Floriano, M. A., Reiners, C. S., Markic, S., \& Avitabile, G. (2009). The uniqueness of teaching and learning chemistry. In I. Eilks \& B. Byers (Eds.), Innovative methods in teaching and learning chemistry in higher education (pp. 23-42). n.p.: RSC Publishing.

Frankel, F. C., \& DePace, A. H. (2012). Visual strategies: A practical guide to graphics for scientists and engineers. New Haven: Yale University Press.

Furlan, P. Y., Kitson, H., \& Andes, C. (2007). Chemistry, poetry, and artistic illustration: An interdisciplinary approach to teaching and promoting chemistry. Journal of Chemical Education, 84, 1625-1630.

Gamow, G. (1993). Mr. Tompkins in paperback. New York: Cambridge University Press.

Gardner, H. (1993). Creating minds: An anatomy of creativity through the lives of Freud, Einstein, Picasso, Stravinsky, Eliot, Graham, and Gandhi. New York: Basic Books.

Gilbert, J. K., \& Treagust, D. F. (2009). Micro, submicro and symbolic representations and the relationship between them: Key models in chemical education. In J. K. Gilbert \& D. F. Treagust (Eds.), Multiple representations in chemical education (pp. 1-8). New York: Springer.
Grohman, M. G., \& Szmidt, K. J. (2013). Teaching for creativity: How to shape creative attitudes in teachers and students. In M. B. Gregerson, H. T. Snyder, \& J. C. Kaufman (Eds.). Teaching creatively and teaching creativity. New York: Springer.

Halpine, S. M. (2004). Introducing molecular visualization to primary schools in California: The STArt! teaching science through art program. Journal of Chemical Education, 81, 1431-1436.

Halpine, S. M. (2008). Real scientists do it with models: The art of science visualization. Teaching Artist Journal, 6(1), 5-19.

Hartquist, T. W., \& Williams, D. A. (1995). The chemically controlled cosmos. New York: Cambridge University Press.

Heid, K. (2008). Creativity and imagination: Tools for teaching artistic inquiry. Art Education, 61(4), 40-46.

Hickman, R., \& Eglinton, K. A. (2015). Visual art in the curriculum. In M. Fleming, L. Bresler, \& J. O'Toole (Eds.), The Routledge international handbook of the arts and education (pp. 145158). New York: Routledge.

Hudson, R. L. (2006). Astrochemistry examples in the classroom. Journal of Chemical Education, 83, 1611-1616.

Jackson, N., Oliver, M., Shaw, M., \& Wisdom, J. (Eds.) (2006). Developing creativity in higher education: An imaginative curriculum. New York: Routledge.

Krajcik, J. S., Slotta, J. D., McNeill, K. L., \& Reiser, B. J. (2008). Designing learning environments to support students' integrated understanding. In Y. Kali, M. C. Linn, \& J. E. Roseman (Eds.), Designing coherent science education: Implications for curriculum, instruction, and policy (pp. 39-64). New York: Teachers College Press.

Lunn, M., \& Noble, A. (2008). Re-visioning science "love and passion in the scientific imagination": Art and Science. International Journal of Science Education, 30(6), 793-805. 
Meyer, J. H. F., \& Land, R. (2003). Threshold concepts and troublesome knowledge: Linkages to ways of thinking and practicing within the disciplines. In C. Rust (Ed.), Improving student learning: Improving student learning theory and practice - ten years on (pp. 412-424). Oxford: Oxford Centre for Staff and Learning Development.

Paige, K., \& Whitney, J. (2008). Vanishing boundaries between science and art: Modeling effective middle years of schooling practice in pre-service science education. Teaching Science, 54(1), 42-45.

Papert, S., \& Harel, I (1991). Situating constructionism. In S. Papert \& I. Harel (Eds.), Constructionism (pp. 1-11). Norwood, NJ: Ablex Publishing Company.

Park, E. J., \& Light, G. (2009). Identifying atomic structure as a threshold concept: Student mental models and troublesomeness. International Journal of Science Education, 31(2), 233-258.

Pullman, B. (1998). The atom in the history of human thought. New York: Oxford University Press.

Rae, A. (1994). Quantum physics: Illusion or reality? New York: Cambridge University Press.

Raeburn, P. (1998). Uncovering the secrets of the red planet. Washington, DC: The National Geographic Society.

Ritchhart, R. (2015). Creating cultures of thinking: The eight forces we must master to truly transform our schools. San Francisco: Jossey-Bass.

Robinson, K. (2006, February). Do schools kill creativity? Retrieved from ted.com/talks/ ken_robinson_says_schools_kill_creativity

Robinson, K. (2009). The element: How finding your passion changes everything. New York: Viking.

Robinson, K. (2010, October). Changing educational paradigms. Retrieved from ted.com/ talks/ken_robinson_changing_education_ paradigms
Robinson, K. (2011). Out of our minds: Learning to be creative. Chichester: Capstone.

Schrödinger, E. (1992). What is life? New York: Cambridge University Press.

Shaw, A. M. (2006). Astrochemistry: From astronomy to astrobiology. Hoboken, NJ: John Wiley \& Sons.

Shulman, L. S. (2013). Those who understand: Knowledge growth in teaching. Journal of Education, 193(3), 1-11.

Smil, V. (1999). Energies: An illustrated guide to the biosphere and civilization. Cambridge, MA: The MIT Press.

Taber, K. S. (2009). Progressing science education: Constructing the scientific research programme into the contingent nature of learning science. New York: Springer.

Talanquer, V. (2015). Threshold concepts in chemistry: The critical role of implicit schemas. Journal of Chemical Education, 92, 3-9.

Talanquer, V. (2016). Central ideas in chemistry: An alternative perspective. Journal of Chemical Education, 93, 3-8.

Wayne, R. P. (1991). Chemistry of atmospheres: An introduction to the chemistry of the atmospheres of earth, the planets, and their satellites. New York: Oxford University Press.

Weimer, M. (2002). Learner-centered teaching: Five key changes to practice. San Francisco: Jossey-Bass.

Wiggins, G., \& McTighe, J. (2005). Understanding by design (pp. 65-81). Alexandria, VA: Association for Supervision and Curriculum Development.

Williams, R. J. P., \& Silva, J. J. R. F. (1996). The natural selection of the chemical elements. New York: Oxford University Press. 


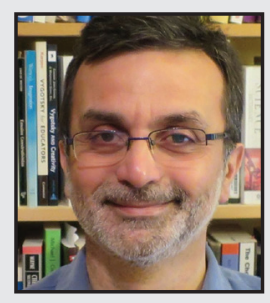

Jailson Lima has a PhD in Inorganic Chemistry from the Universidade de São Paulo, Brazil. He joined the faculty of Vanier College in 2000 and teaches Chemistry in both the Science and Liberal Arts programs. He is currently pursuing an M.Ed. in College Teaching at the University of Sherbrooke, with a focus on identifying and restructuring the misconceptions that incoming students bring from high school. He also collaborates with the Faculty of Education at the University of Cologne and is involved in Concordia University's Art Hives project. His interests include exploring the roles of imagination and creativity in the teaching and learning of science. 